\title{
An investigation into the aspirations and experiences of newly appointed dual diagnosis workers
}

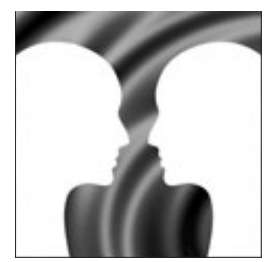

D. F. MCLAUGHLIN ${ }^{1}$ D phil PGCET Bs ( Hons) CMHN Qual DipN RMN (Derek McLaughin), D. SINES ${ }^{2}$ PhD B S ( Hons) RMN RNLD RNT PGCTHE FRCN FRA ( David sines) \& A. LONG ${ }^{3}$ D phil ms counselling Bsc (Hons) psychology R M N ( A n n L o ng)

${ }^{1}$ Lecturer, School of Nursing, University of Ulster, Newtownabbey, Belfast, ${ }^{2}$ Executive Dean and Professor of Community Health Care Nursing - Faculty of Health and Social Care - London South Bank University, Faculty of Health and Social Care, London South Bank University, London, ${ }^{3}$ Honary Fellow of The University of Ulster, The University of Ulster, School of Nursing, Jordanstown, Newtownabbey, UK

Correspondence:

D. F. McLaughlin

School of Nursing

University of Ulster

Shore Road

Newtownabbey

Belfast

BT37 OQB

$U K$

E-mail:derekfmclaughlin@

aol.com
MCLAUGHLIN D. F., SINES D. \& LONG A. (2008) Journal of Psychiatric and Mental Health Nursing 15, 296-305

An investigation into the aspirations and experiences of newly appointed dual diagnosis workers

This qualitative, exploratory study was designed to explore a sample of eight recently appointed dual diagnosis workers' (DDWs) perceptions of their new role and function in Northern Ireland (NI). A semi-structured interview was used and respondents were assured that their anonymity/rights would be protected. All of the narratives were shown to the respondents for their approval prior to going to press. The transcripts were analysed by using a tried and tested analytical framework. Seven key categories emerged from the findings relating to the DDWs perceptions of their: (1)understanding of the term dual diagnosis; (2) hopes; (3) fears; (4) support in their new role; (5) key clinical issues; (6) the positioning of the service; and (7) their overall role and function. This is a new and important area of work in NI. However, to date, no research has been carried out on the topic in the province. Consequently, the findings from this small study could go some way towards helping to shape the future direction of, and bring about some universality to the provision of the dual diagnosis service within different National Health Service Trusts in NI. Further research is required on this new and growing service as well as on the service users' perceptions of the care provided by DDWs. The study will be followed up on an annual basis for 3 years to provide longitudinal data. Generalization of findings requires caution because of the small sample size.

Keywords: alcohol, dual diagnosis, enduring mental distress, illicit drugs, mental health

\section{Introduction}

'The interaction of substance use and severe mental illness can provide an explosive mixture and this dual diagnosis population will probably present the biggest single challenge to our mental health services in the future' (Gournay et al. 1997, p. 14).
The recent introduction of dual diagnosis workers (DDWs) in Northern Ireland (NI) provides a rich opportunity to examine this neophyte group of professionals' perceptions and views on their clinical and academic needs as well as their hopes, aspirations and challenges as they embark upon this innovative and exciting role. 


\section{Literature review}

El Guebaly (1990) reported that the term dual diagnosis includes two interrelated groups of individuals, one presenting with a major substance disorder and a major psychiatric illness and another group whose mental health treatment strategy is compromised by the use of substances. Later, Afuwape (2003) reviewed the dual diagnosis literature and noted that mental health and substance misuse services were often ill-prepared to deal with both conditions. Other presentational states occur when substance use and mental illness interact progressively, leading to deterioration in both presentations. Homelessness may also be associated with dual diagnosis (Williams 2002).

Wright et al. (2000) researched a sample of individuals with psychotic illnesses $(n=124)$ and reported that prevalence rates for dual diagnosis were $33 \%$ for the use of any substance, $20 \%$ for alcohol use only and $5 \%$ for drug use only. In a study in Ireland of people with an enduring mental illness $(n=102)$, results showed that $40 \%$ of the sample reported a lifetime history of illicit drug use (Kamali et al. 2000). Earlier, Menezes et al. (1996) noted a prevalence of $32 \%$ in a study of London inpatients $(n=171)$. Alcohol Focus Scotland (2000) reported that an average of $30 \%$ of people presenting with serious mental illness had also misused alcohol or drugs. Parker (2005) argued that the rates of illicit drug use in NI are similar, but slightly lower than that elsewhere in the UK.

Kamali et al. (2000) found that those using substances reported more suicidal thoughts compared with past or non-substance users, a factor supported by the NI government's mental health strategy (Department of Health Social Services and Public Safety 2003a). ${ }^{1}$ Linszen et al. (1994) concluded that significantly more psychotic relapses occurred with people who used cannabis, noting that use causes relapse in patients with schizophrenia. Moreover, McCrone et al. (2000) reported that a greater proportion of patients with dual diagnosis used inpatient care and emergency clinic services.

In summary to this section, Afuwape (2003) concluded from her analysis of available literature on the subject that:

- dual diagnosis has several definitions;

- those with dual diagnosis comprise a heterogeneous group, although they share similarities in that such individuals often have complex needs;

- that no theory has satisfactorily explained how severe mental illness and substance misuse are related;

\footnotetext{
${ }^{1}$ The Northern Ireland Strategy noted that 'risk factors associated with suicide included combined alcohol and drug misuse, hopelessness and previous suicide attempts ..., p. 25.
}

- prevalence rates vary widely and depends largely on the way dual diagnosis is defined and measured, and the study setting;

- there has been a lack of UK-based dual diagnosis research (p. 14).

\section{Treatment and care strategies}

Drake et al. (1998) concluded that 'integrated approaches have moderate success in reducing the number of days clients spend in hospital, clients' overall symptoms, social problems and improving engagement' (p. 606). Support for integrating psychiatric and psychological treatment techniques for substance misuse has been forthcoming from Barrowclough et al. (2001), Edeh (2002), Moggi et al. (2002), Strathdee et al. (2002). These researchers have suggested that services should be coordinated by local mental health services (p. 5). Furthermore, the Royal College of Psychiatrists (2000) has argued for the integration of mental health and drug, and alcohol response teams.

Similarly, Weaver et al. (2002), using a sample of patients $(n=560)$, demonstrated that collaborative working effectively met the needs of comorbid patients with psychosis. These researchers recommended that both services should work together to develop 'joint policies around assessment, intervention and management' in order to 'ensure earlier identification of comorbidity and more effective interventions' (p. 16).

Johnson (1997), in a UK study, noted that DDWs might suffer high levels of burnout and isolation when managing the care of those with the most challenging needs. Close interprofessional contact and interagency working is therefore vital when working with this group (Alcohol Focus Scotland 2000) to ensure that both patients and professional supporters maintain contact with integrated services.

\section{The NI policy context}

The first NI illicit drug use policy was published in 1995 in an attempt to redress the province's growing substance use problem as noted by Parker (2005). Earlier, Parker (2005) reported that a review of the regional strategy was required, which resulted in the publication of a new drug strategy for NI (1999). This emulated work in England. The implementation of the strategy was overseen by the devolved Northern Ireland Assembly, and was later integrated within mainstream UK policy (Parker 2005).

The new strategy was implemented in 2000 with the stated aim that its effectiveness should be reviewed by the end of 2006. Local action plans were developed by each of the four Health and Social Service Boards (NI), which included protocols on educating and appointing a new 
cadre of DDWs, who would be located with local Community Addiction Teams. In April 2004, the Department of Health Social Services and Public Safety (2004) assumed responsibility for funding the strategy and encompassed its key aims within the national 'investing for health' framework. Currently, eight DDWs are funded within each local community addiction team as recommended by Parker (2005).

Parker (2005) reviewed the effectiveness and efficiency of drug and alcohol services in NI. He reported that local Trusts should take on responsibility for the roll out of DDWs, the development of a prescribing service for opiate users, coupled with related guidance and training for staff. He claimed that steady but uneven progress had been achieved since the implementation of the 2000 strategy and that 'there has been extensive progress uplifting treatment provision and several millions of pounds have been invested' (p. 30). He concluded that the key accomplishments in NI included the implementation of Community Addiction Teams, the advancement of prescribing provision, the involvement of pharmacy services, dual diagnosis working and youth counselling. The review showed that databases had been put in place to monitor access to treatment and prescribed interventions. Education and training programmes had been designed and implemented to enhance the competence and effectiveness of the Community Addiction Team members. Further, local Trusts had commenced work around improved assessment procedures and the measurement of treatment effectiveness. Despite these positive findings, Parker concluded that the treatment provided for individuals with a dual diagnosis remained under-resourced and under-developed, despite steady increases in referrals to the Community Addiction Teams (15\% over the 3 years from 2001 to 2004).

Deloitte Touche (Department of Health Social Services and Public Safety 2003b) conducted an independent review of the effectiveness of the Drug Co-ordination Teams in NI. Their report confirmed that a multidisciplinary team approach should be retained as the lead network, as a 'first stop shop' for local coordination and implementation of drug and alcohol strategies (p. 87). It recommended that these services should be located within four teams, based on Health and Personal Social Services (HPSS) Board boundaries. The report provided a clear mandate for the continuation of an integrated service response that should be 'formally launched and widely promoted' (Department of Health Social Services and Public Safety 2003b, p. 4).

At the time of the current study 10 health and social care Trusts hosted Community Addiction Teams in NI, but not all claim to be adequately resourced (Parker 2005). The future service model for NI is set to follow proposals outlined in the English model for the provision of people with dual diagnosis (Department of Health 2002). This will include in-house development plans for the treatment sector, based on the 'Models of Care' framework approach. Parker (2005) argued that this initiative could improve the efficiency and possibly effectiveness of substance misuse treatment in NI. Currently, plans exist in NI for the implementation of a coordinated care pathway approach, as used elsewhere in the UK.

\section{The aims of the study}

This study used a purposeful sample to explore the aspirations, challenges and experiences of all newly appointed DDWs in NI $(n=8)$ during the first 6 months of their initial date of appointment.

\section{Methodology}

A qualitative, descriptive and exploratory study was employed to explore how recently appointed DDWs in NI perceived their new role. In-depth semi-structured interviews were conducted with the eight respondents in a setting and at a time of the DDWs' choosing.

\section{Access and sample}

All Trust managers that employed DDWs in NI were informed about the study and agreed to participate in the study. A purposive sample was obtained and all eight newly appointed DDWs were contacted and agreed to participate in the study. The characteristics of the sample are presented in Table 1.

Table 1 demonstrates that seven of the mental health nurses were female, with a mean age of 38 years and 4.75 years experience of working with people with drug and alcohol needs. The sample was complemented by one male mental health nurse and one social worker, both of whom had significant experience with this group.

Table 1

Characteristics of the sample

\begin{tabular}{llll}
\hline Age & $\begin{array}{l}\text { Professional } \\
\text { background }\end{array}$ & $\begin{array}{l}\text { Years of experience in } \\
\text { dual diagnosis related } \\
\text { areas of work }\end{array}$ & $\begin{array}{l}\text { Total years of } \\
\text { experience in mental } \\
\text { health practice }\end{array}$ \\
\hline 29 & Nurse & 1 & 5 \\
37 & Nurse & 7 & 12 \\
38 & Nurse & 5 & 14 \\
38 & Nurse & 2.5 & 14.5 \\
39 & Nurse & 10 & 12 \\
40 & Social worker & 10 & 14 \\
46 & Nurse & 7 & 22 \\
50 & Nurse & 3 & 23 \\
\hline
\end{tabular}




\section{Ethical considerations}

The ethical principles outlined by Beauchamp \& Childress (2001) were used as a framework to underpin this study, to ensure that the study was conducted in accordance with professional, legal, moral and social principles throughout the total research process. Ethical actions included obtaining the participants' written consent and informing them of their right to withdraw from the study at any time without remonstration. All notes and recordings were kept securely. Ethical approval was obtained to conduct the study from the University of Ulster Ethics Committee and from the Ethics Committees responsible for local National Health Service research and development activity in NI.

\section{Data collection strategy}

A semi-structured interview guide was designed to facilitate exploration of the aims of the study. Interviews were taperecorded with the respondents' permission. Each structured interview was conducted by the same researcher (DFM). Interviews lasted an average of $1 \mathrm{~h}$.

\section{Data analysis}

The semi-structured interview tapes were transcribed verbatim. Transcripts were then analysed using an adaptation of Burnard's (1991) 'thematic content analysis' framework. Burnard's framework was conceived from the conceptualizations of grounded theory (Glaser \& Strauss 1967), and from content analysis (Berg 1989). Interview transcripts were read and re-read by the three researchers independently to develop understanding and meaning from the raw data. Emerging themes were coded and categorized in Burnard's series of stages by the three researchers independently. The list of categories was then appraised by the researchers, compared and grouped together for the final presentation. Findings were then shared with the participants for their verification. One minor adaptation was made as a result of this action. In keeping with qualitative data reporting, the main themes that emerged are illustrated by citing key narrative responses (Pope \& Mays 1995).

\section{Findings and integrated discussion}

Seven key categories emerged from the data. They were centred on the DDWs' perceptions of: (1) definitions of dual diagnosis; (2) hopes; (3) fears; (4) support in the role; (5) key clinical issues; (6) positioning of services; and (7) role and function.

\section{Definitions of dual diagnosis}

Findings revealed a range of definitions of dual diagnosis. Two DDWs had this to say:

It's difficult to provide a definition but for me it's an area where people are being lost. People are falling between the two areas of mental health and addictions.

I've read that many different definitions but have come to the conclusion that it relates to someone who has a mental health problem and a substance abuse problem and there are different degrees of severity for each of them.

Some DDWs focused their definition on the person's mental health issue. For example:

A dual diagnosis fits people who have a substance misuse issue. They just have to be using it but they also have a coexisting severe and enduring mental health problem.

Another interviewee said he had a clear understanding of the term dual diagnosis but believed that 'others' were trying to tell him how to prioritize casework:

Dual diagnosis means working with people who have both a mental problem and an addiction problem. However, we're continually hearing from 'the top' that we now have to target people with severe enduring mental health problems.

Overall, these findings demonstrated that the participants held a range of understandings of the term dual diagnosis. No standard definition emerged from the data. These findings support those of El Guebaly (1990) and Kamali et al. (2000) who found that dual diagnosis was often associated with the long-term usage of illicit drugs coupled with an enduring mental health problem. Furthermore, Afuwape (2003) concluded from her review of the literature in the UK that while there were many variations on workers' definitions that 'it is generally used to refer to individuals with a severe mental illness and substance misuse problems' (p. 14).

\section{Hopes}

All DDWs $(n=8)$ expressed their hopes for the development of the service, which they considered would benefit people requiring their input. For example:

I would love to see the post develop for this client group. They're very needy. In my experience there are quite a few young folks who are chronically mentally ill and they are being readmitted all the time with drugs and alcohol and they just don't seen to be making good progress.

I wouldn't be going out with the idea that I'm going to save everybody but what I would like to see is a more integrated service for these clients. I hope the service will 
expand because of the growing numbers with a dual diagnosis. I'd also like to see an outreach service.

The hope for further education and training was illustrated by another interviewee:

I'm hoping that there could be some kind of team building in the service. Currently there is a lack of training for staff. Sometimes I'm not sure how to handle something so I tend to back away and say 'well that's someone else's problem'. So, we all need more training to build confidence in staff.

Chiefly, the findings support those of Edeh (2002) who argued that staff working with people presenting with dual diagnosis should be equipped with an amalgamation of skills. The respondents from the present study also acknowledged the need to develop the confidence, capacity and competencies required to respond to the multifarious needs of people presenting complex presentational states. It was suggested that one way of responding to these needs was through the provision of multi-agency training/ learning events, such as those advocated by Strathdee et al. (2002) who also found that there was a need for joint working and shared training between mental health teams and substance services. They recommended that dual diagnostic teams should be recruited from a range of professional backgrounds, with 'varying levels of experience and skills'.

\section{Fears}

All of the DDWs said that they were concerned about taking on this new initiative and that they had no base line to work from as no one else had carried out this role before. Three DDWs communicated:

The fact that it's a completely new post frightens me. It hasn't been here before. I try to go to people for advice but nobody has done it before ... I don't know, sometimes I don't know. I feel that I'm up against a wall because I'm trying to look for help and yes, people are willing to give me advice but there's nobody there that has trod this path before.

Fear because I've always received referrals for people that nobody else wants to work with. The chances of showing improvement would then be limited because we would be working with people resistant to change. We'll be working with people perhaps who have lost faith in themselves and the service.

Fear that I'm going to be asked to reduce the incidence of hospital admissions and readmissions or reduce the incidence of dual diagnosis. I couldn't do that. That's going to take a long time to happen.

Generally, findings illustrated that the interviewees held many fears stemming from their belief that case law had not been established to guide them within the context of new working practices. In addition, respondents were often challenged by clients who feel that they had been let down by the service in the past, which in turn led some of them to perceive that this group of clients might not be able to demonstrate positive outcome response to treatment.

Clearly, staff regarded that certain aspects of their role were stressful, a finding that supports Parker's (2005) conclusion that DDWs often found themselves to be working under pressure and often outwith a defined role specification. One way of reducing role ambiguity might be to more widely promote DDWs' roles and responsibilities, with the aim of enabling services to become more widely established and effective. These findings also complement those arising from the. The Northern Ireland Deloitte Touche study (Department of Health Social Services and Public Safety 2003b).

\section{Support in the role}

Findings indicated that the DDWs perceived that they received their support from four areas, namely their managers, fellow team members, attending clinical supervision and peer group support. The following citations highlight these findings:

My manager's excellent. He's very supportive. He kinda lets me do my own thing and if I've any problems his door's open for me.

The team were really good. They took me out and showed me round the area. Once it was decided which health team I was working in the manager took me under his wing and introduced me to the people who are providing services to this group of clients.

Clinical supervision is important because I'm on my own, being the only one employed in the Trust. I need it as I'll be working with a very difficult client group.

I get a lot of support from other dual diagnosis workers. They're the best people to bounce ideas off, particularly around clinical or complex issues. I've changed some of my ideas and practice after listening to my peer group. When I'm talking to my peer group we discuss the skills component of our job and how to improve practice.

Another DDW perceived that clinical supervision is very important but stated that it had not yet been organized. This participant stated:

Clinical supervision is on the agenda and it is currently being sorted out but there are some difficulties about that now.

However, not all of the DDWs' perceived that they received adequate support. One DDW had this to say: 
I feel I never got any support or preparation for the job. All I heard was 'When can you get started, when can you do this and when can you not?'

Overall, the findings showed that most of the DDWs received good levels of support from their managers and the other DDWs. Most of them attended clinical supervision and considered it enhanced their professional development. Others who were not attending clinical supervision, had requested it. These findings support those of Butterworth et al. (1997), Butterworth \& Woods (1999), and Cottrell (2000, 2001) who used samples of community mental health nurses in their studies. Results demonstrated that the provision of greater managerial support together with a model of contractual, peer clinical supervision were effective at reducing occupational stress and promoting personal and professional development. According to Butterworth \& Woods (1999), exercising individual accountability in a multi-professional environment is essential and clinical supervision is one way of fostering it.

\section{Key clinical issues}

Findings demonstrated that six subcategories emerged from the key category - clinical issues. They were: groundwork, referrals, caseload, clinical assessment, interventions and discharge.

\section{Groundwork}

All participants reported that they had prepared well before attending for interview for the new posts. The following narratives highlight these findings:

I went to a conference and we visited a few specialist units in England. We learned, more or less, how not to do it, because their DDWs just jumped in at the deep end. After a few weeks they were already working a full caseload. I want to be better prepared clinically before I take on a caseload.

I miss patient contact but I'm concerned about taking on a caseload and maybe doing the wrong thing and having to withdraw because of my clinical uncertainty.

I don't want to be going out there thinking, 'Right, I'm the dual diagnosis worker, I know everything', when I clearly know I don't. I feel that I'm holding myself back a bit for a while until I get up to speed clinically.

Generally, the findings are similar to those of Gournay et al. (1997) who demonstrated that many professionals draw upon their previous clinical expertise to prepare them for their specialist roles. Table 1 indicates that the respondents in the present study have significant experience of working with people with mental health and dual diagnosis needs (see Table 1).

\section{Referrals}

Findings demonstrated that the participants were unsure of whom they could accept referrals from and what protocols were required for accepting referrals. Their uncertainties are illustrated in the following narratives:

Initially we [the peer group] thought that only consultant psychiatrists should make referrals, but we think that's too limited. Now we're suggesting that any key worker can refer to us. That means anybody who's in contact with a psychiatrist or has a client with a dual diagnosis.

There isn't a policy on referrals in my area. So, we'll wait and see.

I'd like to take referrals from anyone basically including the voluntary sector because if anything they work with a lot of people with a dual diagnosis.

Overall, the respondents held different views regarding the acceptance of referrals. Further exploration is required on this item to ensure equality of access to services for people with a dual diagnosis. These findings support those of Parker (2005) who considered that greater clarity is required in NI regarding the provision of effective protocols on referral channels and assessment procedures.

\section{Caseload}

Findings indicated that the DDWs intended to carry caseloads of between five and ten clients. The following narratives depict the findings:

... about five to ten people if I'm working directly as the key worker and a lot more if I'm coworking as I'm also a supervisor.

Maybe tenish but I don't know just how complex cases might be. So, I don't know if ten could be too many to work with in depth.

Generally, the findings demonstrated that the question of caseload numbers has been actively considered by all of the DDWs. However, further discussion is required on this topic when the DDWs have established themselves in their new posts and are more aware of what is expected from them in their work.

\section{Clinical assessment}

All of the DDWs mentioned the importance of carrying out clinical assessments. Three respondents said:

I use two assessment scales. One is a form for addictions, which patients fill out. They tick boxes about what they have been using and how often they have used. They also note any recognized problems they're experiencing. After the two assessment forms have been filled out by both of us [the client and the DDW] we collaborate and prioritize the client's problems and assess where they want to start working from. 
I don't know if there's one tool specifically for the assessment of dual diagnosis. Everything that comes along is either a mental health tool or it's an addiction one. Perhaps they just need to be amalgamated.

We've been looking at screening tools in our area that I would like to introduce. Our colleagues could screen clients before referring them to us. Unfortunately, we do not have an assessment tool yet for ourselves. Ideally, it would be good to get some sort of assessment tool that combines both mental health and substance abuse.

The findings demonstrated that all of the DDWs would like to use an assessment tool that amalgamated criteria to assess both mental health and alcohol/drug use issues. These findings support those of Boyd \& Hauenstein 1997) and Parker (2005) who noted that there have been recent attempts to design and implement such integrated assessment tools for use within the DDW service in NI.

\section{Interventions}

Findings depicted that the respondents had a wealth of views on the topic of interventions mainly related to shortor long-term working. For example:

If we work with this client group for a long time their mental health and their harm reduction aspect of substance abuse will improve. The clients will also be much more aware of the side effects of substances and they'll understand the relationship between their behaviour and their mental health. At the point of discharge I expect to have achieved some of those things.

I haven't sat down and discussed how we're going to measure outcomes. How do we really know that people are mentally better or that their 'using' has improved? It would be good to be able to validate that clients have changed. We rely on them telling us that their mental state is better or their 'using' has improved.

I see my input as being fairly brief. I would like to do most of the work in conjunction with key workers that they already know. I think the key workers have lots of skills they're frightened of using.

This same interviewee could see some possible difficulties about this 'brief work', stating:

I make clear from the start that my input is brief, four to six sessions ... I don't know how that's going to work out because training has focused on providing long-term work. But, I don't think that it's my role to do long-term work, it would not be physically possible.

Overall, many of the respondents perceived that they would have a lengthy input into clients' care. They believed that they would be able to see tangible improvement in outcomes relating to clients' mental health, and/or their substance use caused by longer term interventions thus reinforcing similar findings arising from Strathdee et al.'s (2002) study. Furthermore, the findings from the current study corroborate those of Drake et al. (1998), the Royal College of Psychiatrists (2000), Barrowclough et al. (2001) and Moggi et al. (2002), who also concluded that integrated approaches are the way forward for people with a dual diagnosis.

Other respondents perceived that the interventions would be carried out by clients' key workers and that DDWs were likely to have a time limited 'brief' input, which would focus mainly on consultation. Moreover, all of the respondents noted that there was no formal way to audit their interventions, a factor also reported by Mccrone et al. (2000) in Scandinavia.

A balance therefore needs to be struck between the findings arising from the current study regarding respondents' interest in working with this client group on a contractual or sessional basis and the probable benefits that clients would receive if they worked with them longer. In addition, Weaver et al. (2002) recommended that mental health and substance misuse services should work together to develop joint policies around assessment, intervention and management in order to ensure earlier identification of comorbidity and more effective interventions. Researchers have also argued that there is a lack of formal audit procedures to measure the effectiveness of clinical interventions for dual diagnosis services (Gournay et al. 1997, Department of Health Social Services and Public Safety 2003b, Parker 2005).

\section{Discharge}

The issue of discharging clients with a dual diagnosis was presented as a key concern for respondents:

I'd move towards discharging when I felt things were going well. I would discharge them back to the CPN they had initially, so it wasn't another new person.

I think it's important to plan the discharge as we spend a lot of time working with clients on a one-to-one basis. So, they might come to rely on us quite a bit.

All of the DDWs perceived that preparing clients for discharge was a key area that exercised their clinical judgement skills. All respondents believed that clients should be discharged 'back to their key workers', who would normally be community psychiatric nurses. Respondents believed that they had a role in continuing to offer support to the key workers following clients' discharge. This issue poses a contemporary challenge to DDWs within the UK and has been partially resolved in England through the implementation of the care programme approach and integrated care pathway model (Parker 2005). 


\section{Positioning of the dual diagnosis service}

Findings revealed that the DDWs had mixed views regarding where they should be based as illustrated in the following narratives:

I feel protected as the dual diagnosis worker placed within the addictions service.

When I went to the first meeting one of the managers wanted to know who I was working with and when I told her I was a dual diagnosis worker and I was based in 'addictions' her immediate reaction was 'well you shouldn't be there, you should be with us in mental health', so I think it will eventually go down the line of going into the mental health service.

I think we should be sitting independently between the two, but having the ability to bring the two teams together rather than this separation.

Overall, the findings showed that all of the respondents were aware that there were two distinct treatment services providing care for people with a dual diagnosis. Mixed views were held on where their service should be located. Johnson (1997) suggested that effective use could be made of DDWs by employing them as specialist members of Community Mental Health Teams. Other literature focuses on the benefits of the mental health service coordinating the service (Alcohol Focus Scotland 2000, Strathdee et al. 2002, Weaver et al. 2002, Department of Health Social Services and Public Safety 2003b, Parker 2005). Weaver et al. (2002) proposed that collaborative working ensures earlier identification of comorbidity and more effective interventions. Parker (2005) added that addiction teams should act as 'first stop shops' for drug and alcohol problems and recommended that they should be located within local HPSS Boards in NI. In line with previous research, the current findings suggest that the provision of integrated services that address both mental illness and substance use issues are the most promising way forward.

\section{Role}

Findings illustrated that the respondents perceived they had a wide-ranging role:

I've a clinical role working with patients. I also have a role in identifying the needs of other staff and training them. I'm working primarily with mental health staff so I need to look at their training needs in substance abuse.

I would need to carry out an audit on the numbers of people in the Trust that have a dual diagnosis as we don't have figures. That's an assessment of needs at a wider, strategic level.

Overall, the respondents perceived that they had to fulfil several different, but interrelated roles and functions. Find- ings revealed that they work as clinicians, educators, consultants, health promoters and support workers for other staff. These findings complement those of El Guebaly (1990), Gournay etal. (1997), Drake etal. (1998), McLaughlin \& Long (1996), McLaughlin et al. (2000) and Edeh (2002) who reported that a similar range of functions is undertaken by DDWs in NI, England, Scotland and Canada.

\section{Conclusion}

The key findings arising from the eight interviews have been presented and discussed within the context of the respondent's NI experience as newly appointed DDWs and related to relevant research literature. These findings are not unique to DDWs in NI, but mirror experiences found in other parts of the UK, Ireland, Canada and Scandinavia. Overall, findings speak to the need for a clear definition of dual diagnosis and provision of guidance around issues such as referral, assessment and discharge procedures. Further research is required on issues such as the expected role and function of DDWs and where they should be positioned in order to provide the most effective service, which ensures equality of access, and an integrated care programme approach regardless of clients' residency. Evidence identifies that this style of working helps practitioners and clients map out and focus care pathways for people with dual diagnosis more effectively (Moggi et al. 2002, Parker 2005).

This study was the first of its kind in NI. The findings demonstrated that the respondents often felt isolated as they started out on this new and challenging career. Findings revealed that there is a limited amount of literature available on the topic to guide the respondents with the result that they felt they had an inadequate evidence base to inform their practice. Furthermore, findings illustrated that the views they expressed had been developed over the course of their professional lives and were founded mainly on experience.

The findings demonstrated that further research is required on the DDWs clinical role, the interventions they will provide and the size of their caseloads. Other pertinent questions arose from the findings relating to the need for reliable and valid assessment tools that cover both mental health and substance use issues. To date, there are no reliable and valid dual diagnosis assessment instruments. Further, the findings revealed that sometimes the emphasis was placed more on mental ill health, and less on substance use problems. This ambiguity has led the newly appointed DDWs to feel unsure about where they should be placed. We plan to interview the participants again in 12-month time to investigate their perceptions after they have become more established. 


\section{Implications}

There are a number of implications and recommendations for clinicians, managers, educators/researchers and policy makers from this piece of research. The implications from this research are as follows:

- A clear definition of what is a dual diagnosis.

- Guidance on issues such as referral, assessment and discharge are needed.

- Research is needed on the role, function and positioning of DDWs within the NI health and social care services.

- The issue of equality of access for people with a dual diagnosis must be addressed and an integrated care programme approach regardless of where they live in NI.

- A range of research needs to be undertaken in the area of dual diagnosis to guide and inform practice, on issues from assessment to treatment.

\section{Acknowledgments}

We acknowledge the limitations of this small scale study and caution against generalization of the findings. However, even with this caveat, the sample size is justified on the basis of its exploratory nature.

\section{References}

Afuwape S. (2003) Where are we with dual diagnosis (substance misuse and mental illness)? - A review of the literature (November, 2003). Rethink, severe mental illness. Available at: http:// www.rethink.org/dualdiagnosis (accessed March 2007).

Alcohol Focus Scotland (2000) Fact sheet: dual diagnosis - alcohol, drugs and mental health (for workers). Available at: http:// www.alcohol-focus-scotland.org.uk/ (accessed March 2007).

Barrowclough C., Haddock G., Tarrier N., et al. (2001) 'Randomized controlled trial of motivational interviewing, cognitive behaviour therapy, and family intervention for patients with co morbid schizophrenia and substance use disorders'. American Journal of Psychiatry 158, 1706-1713.

Beauchamp T.L. \& Childress J.F. (2001) Principles of Biomedical Ethics, 5th edn. Oxford University Press, New York.

Berg B.L. (1989) Qualitative Research Methods for Social Sciences. Allyn and Bacon, New York.

Boyd M.R. \& Hauenstein E.J. (1997) Psychiatric assessment and confirmation of dual disorders in rural substance abusing women. Archives of Psychiatric Nursing 11, 74-81.

Burnard P. (1991) A method of analysing interviewing transcripts in qualitative research. Nurse Education Today 11, 461-466.

Butterworth T., et al. (1997) It Is Good to Talk. An Evaluation Study of Clinical Supervision in 23 Sites in England and Scotland. University of Manchester, Manchester.

Butterworth T. \& Woods D. (1999) Clinical Governance and Clinical Supervision: Working Together to Ensure Safe and
Accountable Practice - A Briefing Paper. ISBN-1 898992851. School of Nursing and Midwifery and Health Visiting, Manchester.

Cottrell S. (2000) Auditing a clinical supervision training programme. Clinical-supervision.com. Available at: http://www. clinical-supervision.com/article.htm (accessed March 2007).

Cottrell S. (2001) Occupational stress and job satisfaction in mental health nursing: focussed interventions though evidencebased assessment. Journal of Psychiatric and Mental Health Nursing 8, 157-164.

Department of Health (2002) Mental Health Policy Implementation Guide. Dual Diagnosis Good Practice Guide. HMSO, London.

Department of Health Social Services and Public Safety (2003a) Promoting Mental Health - Strategy and Action Plan 2003-2008. HMSO, Belfast.

Department of Health Social Services and Public Safety (2003b) Review of drug co-ordination teams final report. Deloitte \& Touche 19 Bedford Street Belfast BT2 7EJ Northern Ireland.

Department of Health Social Services and Public Safety (2004) 'Investing for Health Framework'. HMSO, Belfast.

Drake R.E., Mercer-McFadden C., Mueser K.T., et al. (1998) Review of integrated mental health and substance abuse treatment for patients with dual disorders, Schizophrenia Bulletin 24, 589-608.

Edeh J. (2002) 'Dual or separate services?', In: Dual Diagnosis, Substance Misuse and Psychiatric Disorders (ed Rassool, G. H.), pp. 204-215. Blackwell Science, Oxford.

El Guebaly N. (1990) Substance abuse and mental disorders: the dual diagnoses concept, Canadian Journal of Psychiatry 35, 261-267.

Glaser D.W. \& Strauss A.L. (1967) The Discovery of Grounded Theory: Strategies for Qualitative Research. Aldine, New York.

Gournay K., Sandford T., Johnson S., et al. (1997) Dual diagnosis of severe mental health problems and substance abuse/ dependence: a major priority for mental health nursing. Journal of Psychiatric and Mental Health Nursing 4, 89-95.

Johnson S. (1997) Dual diagnosis of severe mental illness and substance misuse: a case for specialist services?. British Journal of Psychiatry 171, 205-208.

Kamali M., Kelly L., Gervin M., et al. (2000) The prevalence of co-morbid substance misuse and its influence on suicidal ideation among in-patients with schizophrenia. Acta Psychiatrica Scandinavica 101, 452-456.

Linszen D.H., Dingemans P.M., Lenior M.E., et al. (1994) Relapse criteria in schizophrenic disorders: different perspectives, Psychiatry Research 54, 273-281.

McCrone P., Menezes P.R., Johnson S., et al. (2000) Service use and costs of people with dual diagnosis in South London. Acta Psychiatrica Scandinavica 101, 464-472.

McLaughlin D.F. \& Long A. (1996) An extended literature review of health professionals' perceptions of illicit drugs and their clients who use them. Journal of Psychiatric and Mental Health Nursing 3, 283-288.

McLaughlin D.F., McKenna H. \& Leslie J.C. (2000) The perceptions and aspirations illicit drugs users hold toward health care staff and the care they receive. Journal of Psychiatric and Mental Health Nursing 7, 435-441.

Menezes P.R., Johnson S., Thornicroft G., et al. (1996) Drug and alcohol problems among individuals with severe mental illness in south London, British Journal of Psychiatry 168, 612-619. 
Moggi F., Brodbeck J., Koltzsch K., et al. (2002) 'One-year follow-up of dual diagnosis patients attending a 4-month integrated inpatient treatment'. European Addiction Research 8, pp. 30-37.

Parker H. (2005) Better managing Northern Ireland's alcohol and drug problems - a review of the Northern Ireland alcohol and drug strategies and the efficiency and effectiveness of their implementation. Department of Health Social Services and Public Safety, Belfast. Available at: http://www.dhsspsni.gov.uk/ drugs-alcohol-report-ni-review.pdf (accessed March 2007).

Pope C. \& Mays N. (1995) Reaching the parts other methods cannot reach: an introduction to qualitative methods in health and health services research. British Medical Journal 311, $42-45$.

Royal College of Psychiatrists (2000) Drugs, Dilemmas and Choices. Gaskell, London.

Strathdee G., Manning V., Best D., et al. (2002) Dual diagnosis in a primary care group (PCG) - a step by step epidemio- logical needs assessment and design of a training and service response model. Available at: http://www.nta.nhs.uk/ frameset.asp? u=http://www.nta.nhs.uk?publications/rs2.html (accessed March 2007).

Weaver T., Charles V., Madden P., et al. (2002) Co-morbidity of misuse and mental illness collaborative study (COSMIC) summary of the report. Department of Social Science and Medicine/Centre for Research on Drugs \& Health Behaviour, Imperial College of Science, Technology and Medicine. Available at: http://www.nya.nhs.uk/publications/cosmic.html (accessed March 2007).

Williams H. (2002) Dual diagnosis - an overview: fact or fiction? In: Dual, Diagnosis; Substance Misuse \& Psychiatric Disorders (ed Rassool, H.), pp. 1-12. Blackwell Science, Oxford.

Wright S., Gournay K., Glorney E., et al. (2000) Dual diagnosis in the suburbs: prevalence, need, and in-patient service use. Social Psychiatry and Psychiatric Epidemiology 35, 297-304. 